\title{
Aspiration-Retriever Technique for Stroke with Large Bore Intermediate Catheter : A Single Center Experience
}

\author{
Ji Won Nam, Na Young Jung, Eun Suk Park, Soon Chan Kwon \\ Department of Neurological Surgery, Ulsan University Hospital, University of Ulsan College of Medicine, Ulsan, Korea
}

Objective : Early successful reperfusion is associated with favorable outcomes in acute ischemic stroke (AIS). The purpose of this study was to achieve successful recanalization by a combined mechanical thrombectomy technique, the Aspiration-Retriever Technique for Stroke (ARTS), which is composed of a flexible large lumen distal access catheter and a retrievable stent as the firstline strategy of mechanical thrombectomy.

Methods : We retrospectively reviewed 62 patients with AIS who underwent mechanical thrombectomy from 2018 to 2019 at our institute by a senior neurointerventionalist. Among them, patients who were treated using the ARTS technique with the soft torqueable catheter optimized for intracranial access (SOFIA ${ }^{\circledR}$; MicroVention-Terumo, Tustin, CA, USA) as the first-line treatment were included. Patients who had tandem occlusions or underlying intracranial artery stenosis were excluded. The angiographic and clinical outcomes were evaluated. The angiographic outcome was analyzed by the rate of successful recanalization, defined as a Thrombolysis in Cerebral Infarction score of $2 \mathrm{~b}$ or 3 at the end of all procedures and the rate of successfully achieving the first pass effect (FPE), defined as complete recanalization with a single pass of the device. The clinical outcomes included the National Institutes of Health Stroke Scale (NIHSS) score, modified Rankin Scale (mRS), and mortality.

Results : A total of 27 patients (mean age, 59.3 years) fulfilled the inclusion criteria. The successful recanalization rate was $96 \%(n=26)$ while the FPE rate was $41 \%(n=11)$. The mean post-procedural NIHSS change was -3.0 . Thirteen patients (48\%) showed good clinical outcomes after thrombectomy with the ARTS technique (mRS at 90 days $\leq 2)$. Postoperative complications occurred in seven of 25 patients : hemorrhagic transformation in six patients (22\%) and distal embolization in one patient (4\%). Mortality was $15 \%(n=4)$.

Conclusion : Although the clinical outcomes using the ARTS technique with a flexible large lumen distal access catheter performed as the frontline thrombectomy in patients with AIS were not significantly superior than those of other studies, this study showed a high rate of successful endovascular recanalization which was comparable to that of other studies. Therefore, ARTS using the SOFIA ${ }^{\circledast}$ catheter can be considered as the first choice of treatment for AIS due to large vessel occlusion.

Key Words: Ischemic stroke · Mechanical thrombectomy · Catheters - Aspiration-retriever technique for stroke (ARTS) · Recanalization.

- Received : October 29, 2020 •Revised : December 18, 2020 •Accepted : March 26, 2021

- Address for reprints : Soon Chan Kwon

Department of Neurosurgery, Ulsan University Hospital, University of Ulsan College of Medicine, 877 Bangeojinsunhwando-ro, Dong-gu, Ulsan 44033, Korea

Tel : +82-52-250-7139, Fax : +82-52-250-7139, E-mail : nskwon.sc@gmail.com, ORCID : https://orcid.org/0000-0003-4885-1456

This is an Open Access article distributed under the terms of the Creative Commons Attribution Non-Commercial License (http://creativecommons.org/licenses/by-nc/4.0) which permits unrestricted non-commercial use, distribution, and reproduction in any medium, provided the original work is properly cited. 


\section{INTRODUCTION}

Acute ischemic stroke (AIS) is a leading cause of morbidity and mortality ${ }^{27)}$. As the phrase "time is brain" suggests, the human nervous tissue is vulnerable to ischemic damage, and hypoperfused brain tissue requires immediate therapeutic intervention $^{19)}$. Intravenous (IV) tissue-type plasminogen activator (t-PA) is a standard treatment for AIS to recanalize occluded cerebral vessels ${ }^{25)}$. However, it has several limitations such as a narrow therapeutic window, certain contraindications, and a lower probability of recanalization, especially in cases with large vessel occlusion $(\mathrm{LVO})^{5)}$. Endovascular treatment was introduced to overcome these limitations. Its clinical efficacy has been established through monumental randomized clinical trials ${ }^{1,3,6,21)}$. As a result, guidelines for the early management of AIS by the American Heart and American Stroke Associations suggest mechanical thrombectomy as one of the standard treatments for certain groups of patients with $\mathrm{AIS}^{16)}$. Since its establishment as a standard treatment, studies have been conducted to increase clinical efficacy, such as increasing the recanalization rates and reducing side effects of thrombectomy.

The recanalization rate of mechanical thrombectomy is strongly associated with improved clinical outcomes and reduced mortality ${ }^{18)}$. The first pass effect (FPE), defined as complete revascularization of the occluded large vessel and its downstream territory with only a single use of the device, was introduced as a new indicator of good clinical outcomes ${ }^{28)}$. Moreover, failure of revascularization can lead to increased mortality ${ }^{10)}$. Therefore, successful recanalization by first pass is important and closely related to the choice of technique that is used as the frontline.

The use of new-generation devices has made it possible to achieve high recanalization rates. However, in terms of the technique, the contact aspiration (CA) and stent retriever (SR) techniques have shown similar recanalization rates as the firstline strategy thus far ${ }^{9}$. Moreover, the superiority of one technique over another in terms of the results remains controversial.

The Aspiration-Retriever Technique for Stroke (ARTS) introduced by Massari et al. ${ }^{13)}$ is a combined technique that simultaneously uses a retrievable stent and an aspiration catheter, and this technique was adopted in our study. Several types of aspiration catheters have been developed since the intro- duction of ARTS by Massari. The soft torqueable catheter optimized for intracranial access (SOFIA ${ }^{\circledR}$; MicroVention-Terumo, Tustin, CA, USA) is one such device that has a flexible distal access catheter with a large lumen and a specific design. In particular, it has a soft segment composed of a braid and coil structure and a large diameter. To achieve early successful recanalization, this flexible, large-lumen distal access catheter was used to perform thrombectomy utilizing ARTS. This study was a retrospective analysis that aimed to evaluate the efficacy and safety of combined mechanical thrombectomy using the ARTS technique with the SOFIA ${ }^{\circledR}$ catheter as the first-line strategy of mechanical thrombectomy.

\section{MATERIALS AND METHODS}

This retrospective study was reviewed and approved by the Institutional Review Board and Ethics Committee of Ulsan University Hospital (IRB No. 2020-10-039).

\section{Patient population and inclusion criteria}

The medical records of patients with AIS and LVO who underwent mechanical thrombectomy were retrospectively reviewed. From January 2018 to December 2019, a total of 62 patients underwent mechanical thrombectomy by an experienced neuro-interventionalist at our institute.

This study included patients with AIS and LVO who were only treated using a specific thrombectomy technique called ARTS. The exclusion criteria were as follows : 1) techniques other than ARTS used for endovascular treatment as the firstline treatment, 2) if tandem occlusion, defined as occlusion of the ipsilateral extra- and intracranial arteries, was noted before the procedure, or 3) the presence of underlying intracranial artery stenosis (ICAS).

LVO was defined as occlusion of the proximal intracranial anterior and posterior circulation such as the intracranial internal carotid artery (ICA), the M1 and M2 segments of the middle cerebral artery (MCA), the A1 and A2 segments of the anterior cerebral artery (ACA), intracranial vertebral artery (VA), basilar artery (BA), and the P1 segment of the posterior cerebral artery (PCA) established using computed tomographic angiography (CTA), magnetic resonance angiography (MRA), or digital subtraction angiography (DSA) ${ }^{17)}$. 

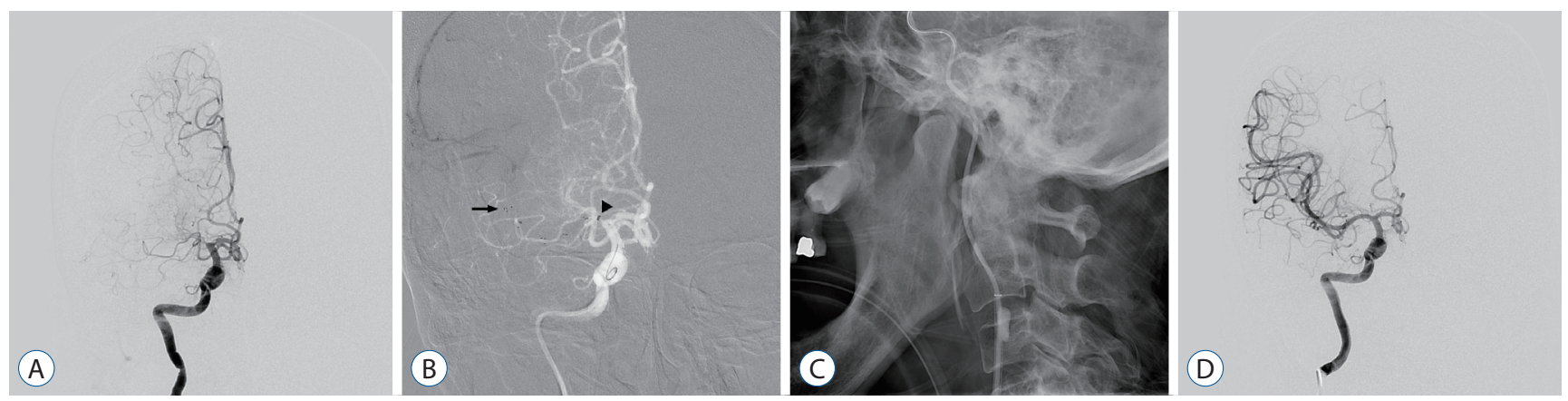

Fig. 1. Angiograms of the ART for right proximal M1 occlusion. A : Pre-treatment angiogram (antero-posterior view) shows the occlusion of right proximal M1 segment. B : A Solitaire stent retriever was deployed within the right M1 segment. Arrow indicates the distal marker of Solitaire stent. Arrowhead points the location of the large bore distal access catheter for aspiration. C: The balloon catheter was inflated for proximal flow arrest (lateral view). D : After mechanical thrombectomy, angiogram shows complete recanalization without distal thrombus migration (Thrombolysis in Cerebral Infarction grade 3).

\section{Endovascular procedure}

ARTS was performed under local anesthesia with conscious sedation. When an $8 \mathrm{Fr}$ balloon-guiding catheter such as Flowgate $^{\circledast}$ (Stryker, Fremont, CA, USA) or Optimo ${ }^{\circledR}$ (Tokai Medical Products, Aichi, Japan) was inserted to access the cerebral vasculature, a 5 or 6 Fr SOFIA ${ }^{\circledast}$ intermediate catheter having a length of $115 \mathrm{~cm}$ was advanced up to the occlusive lesion. A micro-guidewire was used to navigate the distal portion of the site of occlusion. A microcatheter such as Rebar ${ }^{\circledast}$ (EV3, Irvine, CA, USA) was advanced over the guidewire up to near the thrombus. After confirming that the thrombus was in the correct position using a micro-angiogram, a retrievable stent such as Solitaire ${ }^{\circledast}$ (Medtronic Neurovascular, Irvine, CA, USA) or ERIC $^{\circledast}$ (MicroVention-Terumo) was deployed to capture the thrombus, and then the SOFIA ${ }^{\circledR}$ catheter was repositioned just proximal to the thrombus. After 3 to 5 minutes, the stent was retrieved with suction by manual aspiration using a $50 \mathrm{~mL}$ syringe. The stent was retrieved and slowly withdrawn together with the intermediate catheter. This procedure was repeated until successful recanalization was achieved. The procedure is demonstrated in Fig. 1.

\section{Outcome measures}

The primary outcome of ARTS was assessed by the rate of successful recanalization. Successful recanalization was defined as a modified Thrombolysis in Cerebral Infarction (mTICI) score of $2 \mathrm{~b}$ or 3 at the final angiography after all procedures were completed. The secondary outcome was evaluated by the rate of successfully achieving FPE or modified FPE. FPE was defined as complete revascularization (mTICI 3) with a single device pass without additional treatment. Modified FPE was similar but with the difference of an MTICI $2 b$ or 3 . In addition, National Institutes of Health Stroke Scale (NIHSS) scores at admission, day 1 , and day 7 were serially measured to assess clinical efficacy. Adverse events included any complications related to the endovascular procedure itself such as distal embolism in a new vascular territory, or brain hemorrhage detected via a computed tomography (CT) scan of the brain performed within 24 hours of the procedure.

\section{RESULTS}

\section{Baseline characteristics}

Between January 2018 and December 2019, 62 patients underwent mechanical thrombectomy at our institute. Among 62 patients, 37 patients (60.0\%) were treated with ARTS, other 17 patients with CA, and none of patient with SR as the firstline treatment. One of 62 patients $(1.6 \%)$ was treated by only intra-arterial thrombolytic agents, other seven patients only attempted trial of thrombectomy. In trial group, there was no case due to inaccessibility of the distal access catheter near the thrombus. There were two cases of approach failure due to lack of access route. Five patients of them received only cerebral angiography because distal flow was recovered after t-PA administration or chronic vascular occlusion was noted on initial angiography.

Seven of the 37 patients in the ARTS group had underlying tandem lesion or ICAS, another patient had two distinct occlusive lesions (M1 and A3), and two others had a distal occlu- 
ARTS with Large Bore Aspiration Catheter | Nam JW, et al.

Table 1. Details in baseline characteristics $(n=27)$

\begin{tabular}{lc}
\hline & Value \\
\hline Age (years) & $59.3 \pm 15.7$ \\
Women & $12(44.0)$ \\
\hline Medical history & \\
Hypertension & $8(30.0)$ \\
Atrial fibrillation & $7(22.0)$ \\
Diabetes mellitus & $6(22.0)$ \\
Hyperlipidemia & $5(19.0)$ \\
History of cerebrovascular disease & $4(15.0)$ \\
History of coronary artery disease & $6(22.0)$ \\
Antithrombic medication & \\
$\quad$ Antiplatelet & $5(19.0)$ \\
$\quad$ Anticoagulant & $4(15.0)$ \\
Mean initial NIHSS score & $15.3 \pm 5.9$ \\
Intravenous t-PA & $11(41.0)$ \\
Times of (minutes) & \\
From symptom onset to femoral puncture & $235(168.4,100-830)$ \\
From door to femoral puncture & $136(91.6,77-537)$ \\
From femoral puncture to reperfusion & $52(30.0,23-134)$ \\
\hline
\end{tabular}

Values are presented as mean \pm standard deviation (SD), median (SD, range), or number (\%). NIHSS : National Institutes of Health Stroke Scale, t-PA : tissue plasminogen activator

sive lesion (M3). Therefore, a total of 27 patients met the study criteria.

The mean age was 59.3 years (range, 18-90). There were 15 men and 12 women (44\%). The mean baseline NIHSS score was 15.3 (range, 3-27). IV t-PA at the initial stage was administered to only 11 patients (41\%) because of unclear onset time or previously taking anti-thrombotic agents. The median time was 235 minutes from symptom onset to femoral puncture (range, 100-830 minutes), 136 minutes from door to femoral puncture (range, 77-537 minutes), and 52 minutes from femoral puncture to reperfusion (range, 23-134 minutes). The baseline angiographic and clinical characteristics are shown in Table 1.

\section{Radiological and clinical outcomes}

The occlusion sites were identified with 22 cases in the anterior circulation and five cases in the posterior circulation. M1 $(n=13)$ was the most frequent occlusion site, followed by M2 $(n=5)$, BA $(n=4)$, distal ICA $(n=4)$, and P1 $(n=1)$.

After mechanical thrombectomy using ARTS, the rate of
Table 2. Details in angiographic outcomes

\begin{tabular}{lc}
\hline & ARTS with SOFIA \\
\hline Location of thrombus \\
Internal carotid artery & $4(15.0)$ \\
M1 segment of middle cerebral artery & $13(48.0)$ \\
M2 segment of middle cerebral artery & $5(19.0)$ \\
Basilar artery & $4(15.0)$ \\
P1 segment of posterior cerebral artery & $1(4.0)$ \\
Side & \\
Left & $11(41.0)$ \\
Right & $12(44.0)$ \\
Number of stent passage & $2.5(1-9)$ \\
\hline TICl grade & \\
0 \& 1 \& 2a & $1(4.0)$ \\
2b & $4(15.0)$ \\
3 & $22(81.0)$ \\
\hline First pass effect & $11(41.0)$ \\
\hline Modified first pass effect & $13(48.0)$ \\
\hline
\end{tabular}

Values are presented as mean (range) or number (\%). ARTS : AspirationRetriever Technique for Stroke, $\mathrm{TICl}$ : Thrombolysis in Cerebral Infarction

Table 3. Details in clinical outcomes

\begin{tabular}{lc}
\hline & ARTS with SOFIA ${ }^{\oplus}(\mathbf{n}=\mathbf{2 7})$ \\
\hline Postop image findings & \\
Hemorrhagic transformation & $6(22.0)$ \\
Procedure-related complication & \\
Distal embolization & $1(4.0)$ \\
Vessel dissection & $0(0.0)$ \\
Vessel rupture & $0(0.0)$ \\
Vasospasm & $0(0.0)$ \\
Mortality & $4(15.0)$ \\
Clinical outcomes at 3 months & \\
Good (mRS $\leq 2)$ & $13(48.0)$ \\
Poor (mRS $>2)$ & $14(52.0)$ \\
mRS=3 & $3(11.0)$ \\
mRS $=4$ & $6(22.0)$ \\
mRS $=5$ & $2(7.0)$ \\
mRS $=6$ & $4(15.0)$ \\
NIHSS score & \\
At post-procedure & $12.3 \pm 8.4(0-29)$ \\
At 7 days & $11.3 \pm 9.9(0-37)$ \\
\hline Values are presented as mean \pm standard deviation (range) or number $(\%)$. \\
ARTS : Aspiration-Retriever Technique for Stroke, mRS : modified Rankin \\
Scale, NIHSS : National Institutes of Health Stroke Scale
\end{tabular}


successful recanalization defined as a TICI score of $2 b$ or 3 was $96 \%(n=26)$, and the rate of complete reperfusion (mTICI 3) was $81 \%(n=22)$. The rate of FPE was $41 \%(n=11)$ and that of modified FPE was $48 \%(n=13)$. An average 2.5 passes of the device (range, 1-9; median, 2) were required for reperfusion.

The average NIHSS score at admission was 15.3 (range, 3-27; median, 17), the NIHSS score at 24 hours was 12.3, the mean change in the NIHSS score between admission and 24 hours was -3.0 (range, -17 to +9 ; median, -2 ), the NIHSS score at 7 days was 11.3 (range, 0-37; median, 11), and the mean change between admission and 7 days was -4.1 (range, -17 to +19; median, -5). Good clinical outcomes at 3 months (mRS $\leq 2)$ were seen in 13 patients.

Six patients $(22 \%)$ presented with intracranial hemorrhage on the follow-up CT within 24 hours of the procedure, three patients (11\%) underwent decompressive craniectomy due to increased intracranial pressure (ICP), one patient (4\%) from our study group had distal emboli and exhibited slightly aggravated motor weakness.

Two patients who underwent decompressive surgery showed neurological improvement or stability relative to their pre-treatment neurological statuses; one patient, however, died. A total of four patients (15\%) managed using ARTS died, including two from increased ICP and two from other medical conditions that were less relevant to the procedure.

The angiographic and clinical results of the inclusion group are summarized in Tables 2 and 3.

\section{DISCUSSION}

In this study, although the clinical outcomes using the ARTS technique with a flexible large lumen distal access catheter performed as first-line thrombectomy in patients with AIS were not significantly superior than those of other studies, a high rate of successful endovascular recanalization which was comparable to that of other studies was seen.

ARTS, the technique used in our study, was introduced by Massari et al. ${ }^{13)}$ in 2016. It was designed for effective removal of the thrombus, prevention of distal migration of the fragments, and reduction of revascularization time. Massari et al. ${ }^{13)}$ suggested that ARTS was a fast, safe, and effective technique that could compete with conventional techniques. Newer devices for mechanical thrombectomy are being devel- oped every day. Massari et al. ${ }^{13)}$ used the $5 \mathrm{Max} \mathrm{ACE}^{\circledR}$ catheter (Penumbra, Alameda, CA, USA), but owing to the availability of advanced devices, we performed ARTS using the SOFIA ${ }^{\circledR}$ catheter, the next-generation intermediate catheter which has some advantages, one of them being a large diameter.

SOFIA $^{\circledR}$ was initially developed for use as a guiding catheter, but is also widely used as an aspiration catheter nowadays ${ }^{12)}$. First of all, since it was developed as a guiding catheter, it is cheaper than penumbra's aspiration catheter. It has a length of 115 or $125 \mathrm{~cm}$, an outer diameter of 5 or $6 \mathrm{~F}$, an inner luminal diameter of 0.068 or 0.070 inches, and a straight tip. According to Long et al. ${ }^{11)}$, SOFIA ${ }^{\circledR}$ achieved a higher vacuum flow rate $(4.42 \mathrm{~mL} / \mathrm{s})$ than the $5 \mathrm{MAX} \mathrm{ACE}^{\circledR}(4.27-4.36 \mathrm{~mL} / \mathrm{s})$. The hybrid braid/coil design increases navigability of the distal vasculature, even in tortuous vessels. Additionally, the soft distal shaft prevents traumatic vessel access. Its navigability provides adequate stability for microcatheter to select vessels, such as the distal ICA, M1, or M2 segments. Furthermore, its large inner diameter generates sufficient aspiration force and contact area for clot retrieval ${ }^{22,23,26)}$.

CA thrombectomy with SOFIA ${ }^{\circledR}$ reportedly revealed a higher reperfusion rate and shorter procedure time than those with Penumbra ${ }^{\circledR}$ without any significant complications ${ }^{8,12,14,15)}$. Additionally, SOFIA ${ }^{\circledR}$ achieved impressive outcomes and showed potential as the primary aspiration catheter for CA thrombectomy on a recent study ${ }^{2)}$. For these reasons, we expected SOFIA ${ }^{\circledR}$ to yield better outcomes than other catheters. Our study reported a successful recanalization rate of $96 \%$ and a modified FPE rate of $41 \%$. These results are similar with the outcomes reported by Massari et al. ${ }^{13)}$ (97.6\% and 43\%, respectively). However, the good clinical outcome rate in our study was $48 \%$ which was lower than that observed by Massari et al. ${ }^{13)}$ (65.7\%). In addition, our results showed a relatively higher reperfusion rate and greater safety than those seen in other studies that used a similar technique but different aspiration catheters (Table 4$)^{4,7,13)}$.

Our results were not inferior to those of other large-scale studies. Rather, our study showed better outcomes in terms of the recanalization rate (Table 5) ${ }^{9,20,24)}$. The Direct Aspiration First Pass Technique For Acute Stroke Thrombectomy (ADAPT FAST) $(n=192)$ study reported that the CA technique alone achieved successful recanalization (mTICI score $2 \mathrm{~b} / 3$ ) in $78 \%$ of cases. According to the Contact Aspiration versus Stent Retriever for Successful Revascularization (ASTER) tri- 
ARTS with Large Bore Aspiration Catheter I Nam JW, et al.

Table 4. Comparison of outcomes with other studies using combined techniques

\begin{tabular}{|c|c|c|c|c|c|}
\hline & $\begin{array}{l}\text { ARTS, } \\
\text { ours }\end{array}$ & $\begin{array}{l}\text { ARTS, } \\
\text { anterior }\end{array}$ & $\begin{array}{c}\text { ARTS, } \\
\text { Massari et al. }\end{array}$ & $\begin{array}{l}\text { Solumbra, Delgado } \\
\text { Almandoz et al. }\end{array}$ & $\begin{array}{l}\text { Combined, } \\
\text { Hesse et al." }\end{array}$ \\
\hline Case No. & 27 & 22 & 42 & 55 & 184 \\
\hline Catheter & SOFIA & SOFIA & ACE & ACE & $\begin{array}{l}\text { ACE, SOFIA, } \\
\text { CATALYST }\end{array}$ \\
\hline $\mathrm{TICl} 2 \mathrm{~b} / 3$ & $26(96.0)$ & $21(95.0)$ & $41(98.0)$ & $46(84.0)$ & $159(86.0)$ \\
\hline $\mathrm{TICl} 3$ & $22(81.0)$ & $17(77.0)$ & $23(55.0)$ & - & $69(38.0)$ \\
\hline FPE & $11(41.0)$ & $6(27.0)$ & - & - & $47(26.0)$ \\
\hline mFPE & $13(48.0)$ & $8(36.0)$ & $18(43.0)$ & - & - \\
\hline $\mathrm{ICH}$ at 24 hours & $6(22.0)$ & $6(27.0)$ & $2(5.0)$ & $2(4.0)$ & $13(9.0)$ \\
\hline Mortality at 90 days & $4(15.0)$ & $3(14.0)$ & $6(14.0)$ & $16(29.0)$ & - \\
\hline Onset to puncture time, mean (minutes) & 288 & 255 & 360 & 267 & - \\
\hline Puncture to reperfusion time, mean (minutes) & 57 & 60 & - & - & 52 \\
\hline
\end{tabular}

Values are presented as number (\%) unless otherwise indicated. ARTS : Aspiration-Retriever Technique for Stroke, TICl : Thrombolysis in Cerebral Infarction, FPE : first pass effect, mFPE : modified first pass effect, ICH : intracranial hemorrhage

Table 5. Comparison of outcomes with previous large-scale studies

\begin{tabular}{|c|c|c|c|c|c|c|}
\hline & ARTS, ours & ARTS, anterior & ASTER $^{9)}$ CA & ASTER $^{6)} S R$ & ADAPT FAST ${ }^{24)}$ & SWIFT $^{20}$ \\
\hline Case No. & 27 & 22 & 192 & 189 & 100 & 89 \\
\hline $\mathrm{TICl} 2 \mathrm{~b} / 3$ & $26(96.0)$ & $21(95.0)$ & $164(85.0)$ & $157(83)$ & $95(95.0)$ & 75.9 \\
\hline $\mathrm{TICl} 3$ & $22(81.0)$ & $17(77.0)$ & $72(38.0)$ & 73 (38.6) & $51(51.0)$ & - \\
\hline $\begin{array}{l}\text { Change in NIHSS score at } \\
24 \text { hours, mean }\end{array}$ & $-3.0(-17$ to 9$)$ & $-3.2(-17$ to 9$)$ & $-4.8(-6.1$ to -3.6$)$ & $-5.2(6.5$ to -3.9$)$ & -9.9 & - \\
\hline $\mathrm{ICH}$ at 24 hours & $6(22.0)$ & $6(27.0)$ & $87(46.3)$ & $85(46.0)$ & $0(0.0)$ & \\
\hline Mortality at 90 days & $4(15.0)$ & $3(14.0)$ & $35(19.3)$ & $35(19.0)$ & $15(19.0)$ & 17 \\
\hline $\begin{array}{l}\text { Onset to puncture time, } \\
\text { mean (minutes) }\end{array}$ & 288 & 255 & 217 & 235 & 510 & \\
\hline
\end{tabular}

Values are presented as number (\%) unless otherwise indicated. ARTS : Aspiration-Retriever Technique for Stroke, CA : contact aspiration, SR : stent retrieval, $\mathrm{TICl}$ : Thrombolysis in Cerebral Infarction, NIHSS : National Institutes of Health Stroke Scale, ICH : intracranial hemorrhage

$\mathrm{al}$, the successful revascularization rate (mTICI score $2 \mathrm{~b} / 3$ ) was $85.4 \%$ in the CA group and $83.1 \%$ in the SR group, and the complete revascularization rate (mTICI 3 ) was $37.5 \%$ in the CA group and $38.6 \%$ in the SR group. The Solitaire Flow Restoration Device versus the Merci Retriever in patients with acute ischemic stroke (SWIFT) study showed that the revascularization rates were similar with $75.9 \%$ for an mTICI score of $2 \mathrm{~b} / 3$ and $75.9 \%$ for an mTICI score of 3 .

According to previous studies, a higher recanalization rate and FPE were associated with good clinical outcomes ${ }^{10}$. However, the good angiographical results in our study did not lead to good clinical outcomes corresponding to the high reperfusion rate. This may be due to several reasons. First, the portion of posterior circulation was different compared with other studies. The proportion of posterior circulartion in our study was $19 \%$. The rate of those cases was $23.5 \%$ (8/34) in Massari's study, $0 \%$ in Delago's and Hesse's studies (Table 4), $0 \%$ in ASTER trial, 5\% (5/100) in ADAPT FAST trial, 3.4\% (3/89) in SWIFT trial (Table 5). It seemed meaningful to separate the outcomes of anterior circulation from those of posterior circulation. Nevertheless, the results from anterior circulation could not present better clinical outcome (Tables 4 and 5). Second, some patients with AIS who presented related symptoms for more than 6 hours were included in our study. The rates of those patients in the entire group and anterior circulation group were $30 \%(8 / 27)$ and $32 \%(7 / 22)$, respectively. 
Third, some included patients had severe morbidity. Four patients had an initial mRS score of 3 or higher, and three patients suffered cancer in the advanced stage. It contributed unfavorable outcomes unrelated to AIS, such as an aggravated general condition in an advanced cancer patient or tumor lysis syndrome in a lymphoma patient.

Our study has several limitations. This study was retrospective analysis conducted in a single center and had a paucity of inclusion data. Multi-centered, randomized clinical trials will be needed to support our results. In addition, we selected only those cases where the ARTS technique was used. The exclusion of certain cases such as those using CA for proximal ICA occlusion and those frequently requiring rescue therapy due to underlying stenosis affected our results. Nevertheless, the results of our study were useful in demonstrating that the results with ARTS were non-inferior to those of previous largescale studies. In future, studies such as the ongoing ASTER II trial, would provide more valid and specific outcomes for the combined technique.

We performed mechanical thrombectomy with a combination of previously invented devices. The development of the device is also important, but it is necessary to consider how to use it. New techniques should continue to be studied.

\section{CONCLUSION}

This study demonstrated the procedural and clinical efficacy of the ARTS technique using the SOFIA ${ }^{\circledR}$ intermediate catheter. Although the results of this study were not superior in terms of clinical outcomes and safety than those of other established clinical trials, ARTS using the SOFIA ${ }^{\circledR}$ catheter achieved high recanalization and FPE rates. Previous studies have shown a correlation between FPE and the recanalization rate and favorable clinical outcomes, which supports the usefulness of our findings. The low cost, better aspiration force and navigability of the SOFIA ${ }^{\circledast}$ catheter would attract other neurointerventionalists to use this catheter when performing thrombectomy. Therefore, this approach could be a good alternative in terms of high reperfusion rate and cost-effectiveness. In future, large-scale and randomized studies using the combined technique and the same type of aspiration catheter may be necessary to validate our results.

\section{CONFLICTS OF INTEREST}

No potential conflict of interest relevant to this article was reported.

\section{INFORMED CONSENT}

This type of study does not require informed consent.

\section{AUTHOR CONTRIBUTIONS}

\author{
Conceptualization : JWN, SCK \\ Data curation : JWN, NYJ, ESP \\ Formal analysis: JWN, NYJ \\ Methodology : SCK \\ Project administration : SCK \\ Visualization: JWN, NYJ \\ Writing - original draft : JWN \\ Writing - review \& editing : JWN, SCK
}

\section{ORCID}

$\begin{array}{ll}\text { Ji Won Nam } & \text { https://orcid.org/0000-0002-5948-2521 } \\ \text { Na Young Jung } & \text { https://orcid.org/0000-0001-9996-1378 } \\ \text { Eun Suk Park } & \text { https://orcid.org/0000-0002-5090-5284 } \\ \text { Soon Chan Kwon } & \text { https://orcid.org/0000-0003-4885-1456 }\end{array}$

\section{References}

1. Berkhemer $O A$, Fransen $P S$, Beumer $D$, van den Berg LA, Lingsma HF, Yoo AJ, et al. : A randomized trial of intraarterial treatment for acute ischemic stroke. N Engl J Med 372 : 11-20, 2015

2. Brinjikji W, Raz E, De Leacy R, Meila D, Mokin M, Samaniego EA, et al. : MRS SOFIA: a multicenter retrospective study for use of Sofia for revascularization of acute ischemic stroke. J Neurointerv Surg, 2021 [Epub ahead of print]

3. Campbell BC, Mitchell PJ, Kleinig TJ, Dewey HM, Churilov L, Yassi N, et al. : Endovascular therapy for ischemic stroke with perfusion-imaging selection. N Engl J Med 372 : 1009-1018, 2015

4. Delgado Almandoz JE, Kayan Y, Young ML, Fease JL, Scholz JM, Milner AM, et al. : Comparison of clinical outcomes in patients with acute ischemic strokes treated with mechanical thrombectomy using either Solum- 
bra or ADAPT techniques. J Neurointerv Surg 8 : 1123-1128, 2016

5. Deng L, Qiu S, Wang L, Li Y, Wang D, Liu M : Comparison of four food and drug administration-approved mechanical thrombectomy devices for acute ischemic stroke: a network meta-analysis. World Neurosurg 127 : e49-e57, 2019

6. Goyal M, Demchuk AM, Menon BK, Eesa M, Rempel JL, Thornton J, et al. : Randomized assessment of rapid endovascular treatment of ischemic stroke. N Engl J Med 372 : 1019-1030, 2015

7. Hesse AC, Behme D, Kemmling A, Zapf A, Große Hokamp N, Frischmuth I, et al. : Comparing different thrombectomy techniques in five largevolume centers: a 'real world' observational study. J Neurointerv Surg $10: 525-529,2018$

8. Kim YW, Hwang YH, Kim YS, Kang DH : Frontline contact aspiration thrombectomy using SOFIA catheter for acute ischemic stroke: periodto-period comparison with Penumbra catheter. Acta Neurochir (Wien) 161 : 1197-1204, 2019

9. Lapergue B, Blanc R, Gory B, Labreuche J, Duhamel A, Marnat G, et al. : Effect of endovascular contact aspiration vs stent retriever on revascularization in patients with acute ischemic stroke and large vessel occlusion: the ASTER randomized clinical trial. JAMA 318 : 443-452, 2017

10. Linfante I, Walker GR, Castonguay AC, Dabus G, Starosciak AK, Yoo $A J$, et al. : Predictors of mortality in acute ischemic stroke intervention: analysis of the North American solitaire acute stroke registry. Stroke $46: 2305-2308,2015$

11. Long TD, Kallmes DF, Hanel R, Shigematsu T, Halaszyn AM, Wolter J, et al. : Novel aspiration catheter design for acute stroke thrombectomy. J Neurointerv Surg 11 : 190-195, 2019

12. Marnat G, Barreau X, Detraz L, Bourcier R, Gory B, Sgreccia A, et al. : First-line sofia aspiration thrombectomy approach within the endovascular treatment of ischemic stroke multicentric registry: efficacy, safety, and predictive factors of success. AJNR Am J Neuroradiol 40 : 10061012, 2019

13. Massari F, Henninger $N$, Lozano JD, Patel A, Kuhn AL, Howk M, et al. : ARTS (aspiration-retriever technique for stroke): initial clinical experience. Interv Neuroradiol 22 : 325-332, 2016

14. Möhlenbruch MA, Kabbasch C, Kowoll A, Broussalis E, Sonnberger $M$, Müller $M$, et al. : Multicenter experience with the new SOFIA plus catheter as a primary local aspiration catheter for acute stroke thrombectomy.

J Neurointerv Surg 9 : 1223-1227, 2017

15. Nouri N, Ferrigno M, Personnic T, Bala F, Bretzner M, Estrade L, et al. : Real-world thrombectomy using the sofia catheter. World Neurosurg 122 : e1247-e1251, 2019

16. Powers WJ, Rabinstein AA, Ackerson T, Adeoye OM, Bambakidis NC, Becker $\mathrm{K}$, et al. : Guidelines for the farly management of patients with acute ischemic stroke: 2019 update to the 2018 guidelines for the early management of acute ischemic stroke: a guideline for healthcare professionals from the American Heart Association/American Stroke Association. Stroke 50 : e344-e418, 2019

17. Rennert RC, Wali AR, Steinberg JA, Santiago-Dieppa DR, Olson SE, Pannell JS, et al. : Epidemiology, natural history, and clinical presentation of large vessel ischemic stroke. Neurosurgery 85 : S4-S8, 2019

18. Rha JH, Saver JL : The impact of recanalization on ischemic stroke outcome: a meta-analysis. Stroke 38 : 967-973, 2007

19. Saver JL : Time is brain--quantified. Stroke 37 : 263-266, 2006

20. Saver JL, Jahan R, Levy El, Jovin TG, Baxter B, Nogueira RG, et al. : Solitaire flow restoration device versus the merci retriever in patients with acute ischaemic stroke (SWIFT): a randomised, parallel-group, noninferiority trial. Lancet 380 : 1241-1249, 2012

21. Saver IL, Goyal M, Bonafe A, Diener HC, Levy El, Pereira VM, et al. : Stent-retriever thrombectomy after intravenous t-PA vs. t-PA alone in stroke. N Engl J Med 372 : 2285-2295, 2015

22. Shallwani $H$, Shakir HJ, Rangel-Castilla L, Davies JM, Sonig A, Sattur MG, et al. : Safety and efficacy of the sofia (6F) PLUS distal access reperfusion catheter in the endovascular treatment of acute ischemic stroke. Neurosurgery 82 : 312-321, 2018

23. Stampfl S, Kabbasch C, Müller M, Mpotsaris A, Brockmann M, Liebig T, et al. : Initial experience with a new distal intermediate and aspiration catheter in the treatment of acute ischemic stroke: clinical safety and efficacy. J Neurointerv Surg 8 : 714-718, 2016

24. Turk AS, Frei D, Fiorella D, Mocco J, Baxter B, Siddiqui A, et al. : ADAPT FAST study: a direct aspiration first pass technique for acute stroke thrombectomy. J Neurointerv Surg 6 : 260-264, 2014

25. Wardlaw JM, Murray V, Berge E, del Zoppo G, Sandercock P, Lindley RL, et al. : Recombinant tissue plasminogen activator for acute ischaemic stroke: an updated systematic review and meta-analysis. Lancet 379 : 2364-2372, 2012

26. Wong JHY, Do HM, Telischak NA, Moraff AM, Dodd RL, Marks MP, et al. : Initial experience with SOFIA as an intermediate catheter in mechanical thrombectomy for acute ischemic stroke. J Neurointerv Surg 9 : 1103-1106, 2017

27. Writing Group Members, Mozaffarian D, Benjamin EJ, Go AS, Arnett DK, Blaha MJ, et al. : Executive summary: heart disease and stroke statistics--2016 update: a report from the American Heart Association. Circulation 133 : 447-454, 2016

28. Zaidat 00, Castonguay AC, Linfante I, Gupta R, Martin CO, Holloway $W E$, et al. : First pass effect: a new measure for stroke thrombectomy devices. Stroke 49 : 660-666, 2018 